\title{
UTILIZAÇÃO DE JULGAMENTOS PSICOFÍSICOS PARA INVESTIGAÇÃO DA INTELIGIBILIDADE DE FALA NO RUÍDO EM OUVINTES COM AUDIÇÃO NORMAL E PERDA AUDITIVA.
}

\author{
Sueli Aparecida Caporali, \\ Universidade Metodista de Piracicaba, \\ José Aparecido Da Silva, \\ Universidade São Paulo, Ribeirão Preto,
}

\begin{abstract}
Resumo: A inteligibilidade de fala no ruído foi investigada neste estudo utilizando-se julgamentos psicofísicos em grupos de jovens ouvintes com audição normal, e em jovens e idosos com perda auditiva. Foram utilizadas escalas intervalar e de razão para se estimar a inteligibilidade de sentenças apresentadas ipsilateralmente com ruído "cocktail” em diferentes relações sinal/ruído. De acordo com os resultados obtidos, a inteligibilidade das sentenças aumenta conforme aumenta a relação sinal/ruído, nos três grupos. Foram encontradas diferenças significativas entre os grupos quanto a inteligibilidade das sentenças. As escalas psicofísicas foram válidas e confiáveis para mensurar a inteligibilidade de fala. Entretanto, outros estudos são necessários antes de sua utilização na prática clínica.
\end{abstract}

Palavras-chave: Inteligibilidade de fala, psicofísica, ruído

\section{USING PSYCHOPHYSICAL JUDGMENTS TO INVESTIGATE SPEECH INTELLIGIBILITY IN BACKGROUND NOISE IN NORMAL HEARING AND HEARING IMPAIRED SUBJECTS.}

\begin{abstract}
The speech perception in background noise was investigated through psychophysical judgments in groups of young listeners with normal hearing, adults and elders with hearing loss. Ratio and interval scales were used to estimate the intelligibility of everyday-sentences presented with cocktail noise at three different signal-to-noise ratios. According to the results, the intelligibility of sentences improved as the signal-to-noise ratio increased, which was observed in the three groups, although differences between groups was found in the intelligibility judgments. Both psychophysical scaling methods were valid and reliable to perform this evaluation which showed to be effective to measure speech intelligibility. However, further studies are desirable before clinical usage can be done with this evaluation method.
\end{abstract}

Key-words: Speech intelligibility, psychophysics, noise

A percepção de fala em ambiente ruidoso tem sido investigada por inúmeros pesquisadores. A metodologia psicofísica tem sido utilizada para mensurar atributos perceptuais da fala (Fucci, Domyan, Ellis, \& Harris, 1994), pois os testes psicofísicos podem ser usados para avaliar a impressão dos observadores, isto é, a relação entre o estímulo físico e a sensação que ele produz.(Stevens, 1975).

Artigo recebido para publicação em 19/09/2003; aceito em 09/12/2003. Endereço para corresp.: Sueli Aparecida Caporali Fonoaudiologia UNIMEP - Rodovia do Açúcar, Km 156 - CEP: 13400-911 - Piracicaba, SP, Brasil - E-mail: sueli.caporali@merconet.com.br
Muitos estudos têm mostrado que os julgamentos de inteligibilidade são monotonicamente relacionados com a relação sinal/ruído e com a quantidade de degradação do sinal de fala por filtros (Cox \& McDaniel, 1984; Nakatami \& Dukes, 1973).

Este estudo teve como objetivo avaliar as habilidades de ouvintes jovens com audição normal e jovens e idosos com perda auditiva em freqüências agudas para realizar julgamentos psicofísicos de amostras de fala com ruído, usando escalas de razão e intervalar. Neste estudo a inteligibilidade de fala foi definida como "quão bem a fala é entendida". 


\section{Método}

Participantes. 60 ouvintes realizaram audiometria tonal liminar e logoaudiometria, antes de realizar os julgamentos psicofísicos.

Grupo 1 - Vinte mulheres jovens com audição normal. Idade variou entre 21 e 38, sendo a média de 23,30.

Grupo 2 - Vinte jovens, sendo dezoito homens e duas mulheres, cuja idade variou entre 29 e 50 anos de idade com média de 40,45 . Os sujeitos apresentavam perda de audição neurossensorial em freqüências agudas a partir de $3000 \mathrm{~Hz}$.

Grupo 3 - Vinte idosos, sendo dez homens e dez mulheres, cuja idade variou entre 60 e 77 anos de idade com média de 66,85 . Os sujeitos apresentavam configuração audiométrica semelhante ao grupo 2, comprovada estatisticamente.

Estímulos. Os estímulos usados foram 22 sentenças do dia-a-dia em português (Oliveira, 1992). Veja no anexo 1. A sentenças e o ruído "cocktail" foram gravados separadamente utilizando um computador em um estúdio profissional. Três séries de sentenças foram produzidas em ordem aleatória. O primeiro estímulo foi precedido por uma sentença: "Por favor, ouça cuidadosamente todas as sentenças". Então a primeira sentença foi apresentada seguida por oito segundos de intervalo para realização do julgamento antes da próxima sentença.

Julgamentos Psicofísicos. Os três grupos foram divididos ao meio, ou seja, formaram dois subgrupos de acordo com a tarefa psicofísica a ser realizada. Metade de cada grupo $(\mathrm{N}=10)$ realizou estimativas de categoria, com intervalo de 1 a 9 e a outra metade $(\mathrm{N}=10)$ realizou estimativas de magnitude com módulo. Os sujeitos que realizaram estimação de magnitude foram treinados antes de começarem as tarefas. Os sujeitos foram informados que eles deveriam avaliar as sentenças em termos de inteligibilidade.

Procedimento. As sentenças com o ruído cocktail ipsilateralmente foram apresentadas aos sujeitos em três ordens aleatórias no ouvido direito. $\mathrm{O}$ nível de apresentação das sentenças foi na intensidade de 40dBNS (decibel nível de sensação) relacionado as médias de limiar de cada sujeito, obtido nas freqüências de 500, 1000 and $2000 \mathrm{~Hz}$. O nível do ruído sofreu variação.

$$
\begin{aligned}
& \text { Condição 1: Relação sinal/ruído -5dB. } \\
& \text { Condição 2: Relação sinal/ruído 0dB. } \\
& \text { Condição 3: Relação sinal/ruído +5dB. }
\end{aligned}
$$

\section{Resultados e Discussão}

Os resultados mostraram que todas as escalas psicofísicas foram concordantes em relação ao julgamento de inteligibilidade de fala. As Figuras 1 A, B e C, mostram as médias dos julgamentos de categoria para as sentenças com ruído "cocktail" nos três grupos para as três relações sinal/ruído. As Figuras $2 \mathrm{~A}$, B e $\mathrm{C}$ mostram as estimativas de magnitude.
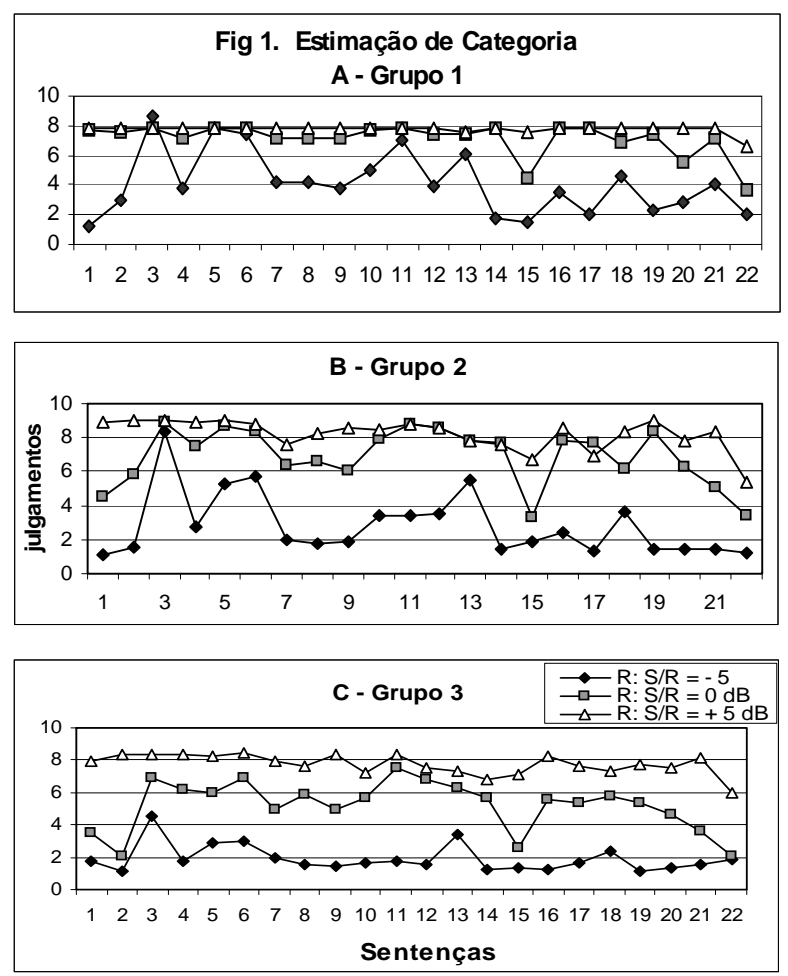

Figura 1. Comparação entre três grupos quanto a inteligibilidade de fala no ruído cocktail em três diferentes relações sinal/ ruído. Dados expressos pela média aritmética, sendo dez sujeitos em cada grupo. Cada uma das abcissas representa uma sentença diferente. A - Grupo 1; B-Grupo 2; C-Grupo 3.

A correlação de Pearson entre estimação de magnitude e categoria foi significativa, especialmente nas relações sinal/ruído -5 and $0 \mathrm{~dB}$ em todos os grupos. Isto sugere boa confiabilidade das estimativas de 
inteligibilidade, independente da escala utilizada. Entretanto, na relação sinal/ruído $+5 \mathrm{~dB}$, os coeficientes obtidos para os grupos 1 e 2 mostraram-se baixos, principalmente no grupo 2, indicando baixa confiabilidade entre as duas escalas. Veja na Tabela 1:

Tabela 1. Coeficiente de correlação entre escalas psicofísicas dos três grupos para cada relação sinal/ruído. EM - Estimação de Magnitude; EC - Estimação de Categoria:

\begin{tabular}{lcccc}
\hline Sentenças & $\begin{array}{c}\text { Relação } \\
\text { sinal/ruído }\end{array}$ & $\begin{array}{c}\text { Grupo } \\
1\end{array}$ & $\begin{array}{c}\text { Grupo } \\
2\end{array}$ & $\begin{array}{c}\text { Grupo } \\
3\end{array}$ \\
\hline EC X EM & $-5 \mathrm{~dB}$ & $0,87^{*}$ & $0,95^{*}$ & $0,87^{*}$ \\
EC X EM & $0 \mathrm{~dB}$ & $0,85^{*}$ & $0,84^{*}$ & $0,80^{*}$ \\
EC X EM & $+5 \mathrm{~dB}$ & 0,50 & 0,14 & $0,79^{*}$ \\
\hline
\end{tabular}

$* \mathrm{p} \leq 0,01$
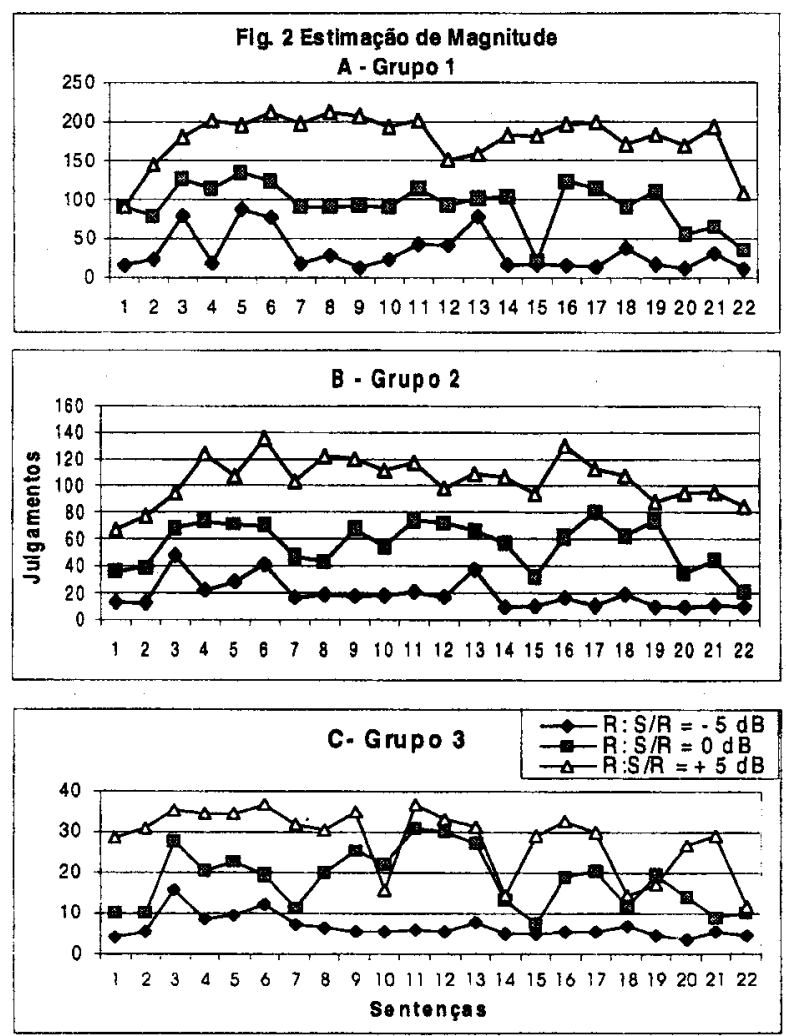

Figura 2. Comparação entre três grupos usando estimação de magnitude da inteligibilidade de fala com ruído "cocktail" em três diferentes relações sinal/ruído. Dados expressos pela média geométrica de dez sujeitos em cada grupo. Cada barra na abcissa representa uma sentença diferente. A - Grupo 1; B Grupo 2; C-Grupo 3.
A maior parte dos resultados estão em concordância com Purdy e Pavlovic (1992), e Mantelatto e Silva (2000a), que encontraram resultados semelhantes comparando sensibilidade dos procedimentos escalares através de métodos psicofísicos. Possivelmente, os baixos coeficientes encontrados na relação sinal/ruído $+5 \mathrm{~dB}$ nos grupos de jovens com audição normal e com perda é devido ao fato dos sujeitos atribuírem altos escores para todas as sentenças nos julgamentos de categoria, atingindo o limite de saturação da escala. O mesmo não aconteceu com os grupos de jovens que realizaram estimação de magnitude.

Os julgamentos mostraram que a inteligibilidade de fala cresce conforme aumenta a relação sinal/ruído. Os três grupos usaram números pequenos na relação sinal/ruído $-5 \mathrm{~dB}$, indicando consistentemente um decréscimo da inteligibilidade de fala e números mais altos para as relações 0 e $+5 \mathrm{~dB}$. Estes resultados foram concordantes com os estudos de Cox e McDaniel (1984) e Nakatami e Dukes (1973), os quais mostraram que julgamentos de inteligibilidade de fala são monotonicamente relacionados a relação sinal/ruído.

A análise de variância (ANOVA) dos escores dos sujeitos que realizaram escala de categoria mostraram diferença estatisticamente significativa entre grupos $[\underline{F}(2,27)=6,361 ; \underline{p}<0,01]$ e relação sinal/ruído $[\underline{F}(1,27)=67,67 ; \underline{p}<0,01]$. Para estimação de magnitude houve diferença para a relação sinal/ruído $[\underline{F}(2,54)=31,895 ; \underline{p}<0,01]$ e diferença marginal somente entre grupos $[\underline{F}(2,27)=2,572, \underline{p}$ $<0,1]$.

As Figuras 1 A, B, C and 2 A, B, C mostram os julgamentos realizados pelos três grupos. Os escores utilizados pelo grupo 1 foram mais altos comparados com os escores nos grupos que apresentam perda auditiva (2 e 3). Estes dados concordam com Pekkarmen, Salmivalli e Suonppa (1990), que relataram que a percepção de fala depende muito mais do estímulo mascarador em relação ao espectro, freqüência em proporção ao sinal de fala apresentado e a configuração audiométrica.

Pode-se também concluir que os escores de inteligibilidade de fala foram afetados pela idade, pois houve diferenças entre escores dos grupos 2 e 3 , com similares perdas auditivas. Outros estudos 
também encontraram que ouvintes idosos apresentam performance mais rebaixada quando comparada a ouvintes para fala apresentada no ruído, entretanto eles usaram outro instrumento de avaliação, como escores de reconhecimento de fala (Barry \& Kidd, 1981).

Estes dados também apontam que as escalas psicofísicas são confiáveis e válidas para mensurar a inteligibilidade de fala no ruído. Os julgamentos de inteligibilidade de fala foram afetados por fatores como perda de audição e idade. Mais estudos são necessários para examinar o potencial das escalas psicofísicas para mensurar a inteligibilidade de fala no ruído, incluindo os efeitos da idade e perda auditiva para a percepção de fala.

\section{Referências Bibliográficas}

Barry, S.K., \& Kidd, G. (1981). Psychophysical scaling of distorced speech. Journal of Speech and Hearing Research, 46, 44-47.

Cox, R.M., \& McDaniel, D.M. (1984). Intelligibility ratings of continuo discourse: application to hearing aid selection. Journal of the Acoustical Society of America, 76, 758-766.

Fucci, D., Domyan, S., Ellis, L., \& Harris, D. (1994). Magnitude-Estimation: an effective method for the measurement of the quality of filtered speech. Perceptual and Motor Skills, 78, 348-350.

Mantelatto, S.A.C., \& Da Silva, J.A. (2000a). Inteligibilidade de fala e ruído: um estudo com sentenças do dia-a-dia. Pró Fono, 12, 48-55.

Nakatami, L.H., \& Dukes, K.D. (1973). A sensitive test of speech communication quality. Journal Acoustical Society American, 53, 1083-1092.

Oliveira, S.T. (1992). Avaliação da percepção de fala utilizando sentenças do dia a dia. Dissertação de mestrado, PUC - SP, São Paulo.

Pekkarmen, E., Salmivalli, A., \& Suonppa, J. (1990). Effect of noise on word discrimination of subjects with impaired hearing compared with those with normal hearing. Scandinavian Audiology, 36, 19-31.

Purdy, S.C., \& Pavlovic, C.V. (1992). Reliability, sensitivity and validity of magnitude estimation, category scaling and paired-comparison judgments of speech intelligibility by older listeners. Audiology, 31, 254-271.

Stevens, S. S. (1975). Psychophysics: introduction to its perceptual, neural, and social prospects. New York: Wiley.

Anexo 1 - Sentenças do dia-a-dia (Oliveira, 1992).

1. Poderia passar a manteiga.

2. Os ratos se escondem dos gatos.

3. Amanhã sairemos sem falta.

4. A tia dele foi nos visitar no Sábado.

5. Pensei que você tivesse ido embora.

6. Fui ao cinema depois do trabalho.

7. A televisão quebrou no meio do filme.

8. Eu não sei se isto é possível.

9. Tomei um copo de suco de limão.

10. Tocamos violão a noite inteira.

12. Todo mundo sabia que ele era assim.

13. Tenho saudades dos velhos tempos.

14. Eles chegaram muito tarde.

15. Coloquei todas as minhas roupas no armário.

16. Pedi uma pizza para viagem.

17. Pegue a caneta para mim.

18. O ônibus parou três vezes durante a viagem.

19. A professora passou a lição de casa para os alunos.

20. O cachorro latiu o dia inteiro.

21. O pedaço de pão que você não comeu está no prato.

22. Perguntei para você onde tinha ido. 